\title{
ESTUDIO DEL COMPORTAMIENTO DEL CONSUMIDOR CHILENO EN PINTEREST
}

Araya Collao, Alexandra Constanza Universidad Católica del Norte, Chile aac036@alumnos.ucn.cl

Castillo Bravo, Eduardo Esteban Universidad Católica del Norte, Chile E.Castillo.B@hotmail.com

Galleguillos Miranda, Constanza Valeska Universidad Católica del Norte, Chile galleguillos1305@gmail.com

López, Manuela ${ }^{1}$ Universidad de Murcia, España manuela.lopez@um.es

Material original autorizado para su primera publicación en la revista académica REDMARKA. Revista Digital de Marketing Aplicado.

https://doi.org/10.17979/redma.2018.01.020.4834

Recibido: 30 octubre 2017

Aceptado: 05 abril 2018

\section{Resumen}

Este trabajo presenta una investigación realizada acerca de Pinterest. La saturación de los medios tradicionales unido al estancamiento de redes sociales como Facebook y Twitter han provocado que los consumidores centren su atención en otras redes sociales como es el caso de Pinterest. Sin embargo, dado su novedad, las empresas aún no tienen claridad acerca de cómo evitar fracasos y

\footnotetext{
${ }^{1}$ Profesora Contratada Doctora en el Departamento de Marketing de la Universidad de Murcia, España
}

Año XI, Número 20, (2018), vol. 1 pp. 201-229 http://www.redmarka.net/ ISSN 1852-2300 
sacar el máximo provecho de esta nueva vía de comunicación. Por lo tanto, este trabajo tiene como objetivo analizar el comportamiento del consumidor chileno en Pinterest. Para ello se realizó un estudio de Pinterest en Chile para conocer las características y las funciones que eran más utilizadas por los usuarios de esta red social, además de cómo interactuaban con las organizaciones. Este estudio es el primero que se realiza formalmente en Chile, por lo que contribuye tanto a la literatura como a la práctica del Marketing online en dicho país.

Palabras clave: Pinterest, redes sociales, Chile

\section{Abstract}

Traditional media saturation and the social network sites standstill have caused consumers migrate from Facebook and Twitter to new social network sites such as Pinterest. However, given the novelty of Pinterest, companies do not know how to take advantage of this new communication channel. Therefore, the objective of this study is to analyze the consumers' behavior of Chilean in Pinterest. A survey was developed in which the most used Pinterest features and the ways consumers interact with companies on this social network site were examined. To the best of our knowledge, this is the first study that analyzes the consumers' behavior of Chilean in Pinterest contributing both theoretically and practically to marketing online.

Keywords: Pinterest, social network sites, Chile 


\section{INTRODUCCIÓN}

Con el paso de los años los consumidores han cambiado en cuanto a los medios de comunicación que utilizan. Una de las revoluciones más importantes que se han vivido fue la irrupción del Internet (Montes, 2010), ya que cada vez son más las personas que tienen acceso a este medio. En enero de 2015 , el $42 \%$ de la población mundial tenía acceso a Internet, y en el mismo período de 2016, el acceso había aumentado al 46\% (We are social, 2016). Esto ha llevado a que los medios que utilizan las personas para entretenerse y/o informarse hayan cambiado. Muchos individuos están sustituyendo los medios tradicionales como la televisión, radios o revistas por Internet (EGM, 2013). Esto ha motivado a las empresas a utilizar este medio para llevar a cabo sus campañas de comunicación. Las herramientas que se usan para realizar acciones de marketing en Internet son muy variadas, desde sitios web corporativos hasta publicidad en páginas de interés del público objetivo.

En los últimos años, una de las herramientas más utilizada por las marcas en Internet han sido las redes sociales. Esto se debe principalmente a la gran cantidad de personas que usan estos medios a nivel mundial. En 2016, el número de usuarios de redes sociales ya supera los 4 billones de personas (Global Web Index, 2016). En cuanto a las empresas que usan las redes sociales, en 2013, 385 de las organizaciones incluidas en el Ranking Fortune 500 tenían un perfil en al menos una red social (Barnes, 2014). En lo que respecta al registro de nuevos usuarios, la mayoría de las redes sociales han seguido creciendo, pero las más populares como Facebook y Twitter ralentizaron su crecimiento entre 2014-2015, mientras que Pinterest fue la red social que más creció con una tasa del $43 \%$ en el mismo periodo, llegando a los cien millones de usuarios (EGM, 2013).

Lo expuesto anteriormente demuestra que las redes sociales más tradicionales se han estancado en el último tiempo debido principalmente a lo intrusivo de su contenido y a la saturación publicitaria de las mismas (González, 2013). El estudio de la consultora PEW Research (2013) confirma esta información y determinó que 
el $61 \%$ de usuarios de Facebook están cansados de esta red social. De hecho, uno de los aspectos que debe cuidarse mucho por parte de las marcas anunciantes es que el usuario de las redes sociales no sienta que la publicidad o las empresas invaden sus espacios personales o sociales, ya que se arriesgan a que las personas sientan aversión contra esas marcas intrusivas (Logan et al., 2012). Es por ello que es de suma importancia encontrar la forma de llegar al público objetivo sin abrumarlo e idealmente que los mismos clientes busquen los productos o servicios ofrecidos (González, 2013).

Teniendo en cuenta lo antes descrito, este estudio está centrado en Pinterest, una red social visual, en la que cada persona sigue sus intereses personales a través de imágenes compartidas por las demás personas. Cada usuario guarda en sus álbumes personalizados (perfil) tanto las imágenes recopiladas por otros usuarios, recolectadas de la web o imágenes de autoría propia, para organizar, compartir y coleccionar sus gustos e intereses. Cada una de las imágenes tiene disponible un enlace externo a un sitio web que contiene información adicional relacionada con la imagen (González, 2013). Cabe destacar que Pinterest no vende publicidad como hasta ahora lo hacen las redes sociales más populares, actualmente sólo existe la opción de promoción pagada en Estados Unidos, Canadá y el Reino Unido. Por lo tanto, la forma que tienen las empresas para realizar marketing a través de Pinterest es creando su propio perfil y añadir imágenes de sus productos y marcas que sean atractivas para el público. De esta forma propiciará que los usuarios busquen por sí mismos información acerca de los productos en los cuales se interesan realmente y no se les fuerce a ver publicidad, lo que evita que éstos se sientan abrumados por los anuncios.

El problema que se visualiza en este momento es que al ser una red social nueva, las empresas aún no tienen claridad acerca de cómo evitar fracasos y sacar el máximo provecho de esta nueva vía de comunicación. Un ejemplo concreto es una campaña fallida realizada por IKEA en 2012, la cual fracasó porque a pesar de que los usuarios participaron en ella no se logró un nexo entre sus productos y 
los futuros planes de sus consumidores (Phillips et al., 2014). Es por esto que se analizarán a los usuarios de Pinterest con el fin de determinar el efecto que tiene en ellos las estrategias de las empresas en esta red social, ya que si bien existen recomendaciones para que éstas la utilicen, no hay ningún estudio que valide que las acciones recomendadas sean efectivas. De este modo, el fin de la presente investigación es analizar el comportamiento del usuario chileno de Pinterest.

\section{DISCUSIÓN BIBLIOGRÁFICA}

\subsection{Redes sociales}

Las redes sociales son "sitios que permiten a los usuarios la creación de un perfil personal o corporativo permitiendo conectarse con los demás, invitando amigos y enviando mensajes instantáneos, proporcionando una comunicación más rápida y fluida" (Kaplan \& M. Haenlein, 2010). Actualmente los usuarios de redes sociales ya superan los cuatro billones de personas en el mundo (Global Web Index, 2016). En América Latina las personas pasan en promedio 8.67 horas diarias en redes sociales y el $95.8 \%$ de las personas que navega en Internet tiene cuenta en al menos una red social (ComScore, 2014). En el caso de Chile, esta última estadística asciende a $97.1 \%$ (ComScore, 2014). Estos datos explican el por qué hace algunos años las empresas comenzaron a incluir las redes sociales en sus estrategias de marketing y las utilizan para posicionarse dentro del mercado, construir marca y relacionarse con sus clientes y/o seguidores (Harris \& Rae, 2009). Por otro lado, pueden conseguir datos de la conducta natural de sus seguidores, permitiéndole a la empresa explorar y analizar los patrones de comportamiento de éstos (Hogan, 2008).

\subsection{Efecto de las redes sociales en el consumidor}

Las empresas cada día deciden incorporar las redes sociales a las campañas de comunicación de marketing debido a la influencia que éstas tiene sobre los consumidores (Sicilia et al., 2016). Se generan relaciones a largo plazo con sus clientes a través de este medio (Yu, 2014), produce boca a boca positivo (Chow \& 
Shi, 2015), satisfacción, lealtad a la marca y confianza (Sicilia et al., 2016). Además, son capaces de crear lazos emocionales e incrementar la intención de compra hacia sus productos (Sicilia et al., 2016).

El $81 \%$ de los usuarios reconoce haber conocido o adquirido un producto a través de las conexiones y opiniones en redes sociales (Catalyst \& Forrest Consulting, 2016) y un tercio de los usuarios de Internet utilizan las redes sociales para obtener información sobre una empresa o producto (Global Web Index, 2016). A través de sus perfiles en las redes sociales las firmas dan a conocer sus productos y marcas. Además, entregan una mayor información a los usuarios y proporcionan asistencia. De esta forma, los usuarios pueden visitar, seguir o ser parte de dichos sitios web. De hecho, estos perfiles corporativos reúnen a las personas que se identifican con la marca o que quieren saber información específica, como precios, ofertas, novedades o seguir eventos promocionales (Global Web Index, 2016).

Lo mencionado en los párrafos anteriores refleja la importancia de estas redes en la actualidad para las empresas. Éstas utilizan las redes sociales con diferentes fines y el marketing se debe adaptar continuamente al contenido que ellas quieran entregar a sus clientes, sembrando base para las promociones que se realicen. Lo que se debe buscar es la participación continua, escuchar y dialogar con los seguidores que se tengan empatizando con ellos (Moya, 2014). Las empresas deben responder a la interrogante ¿qué redes sociales se ajustan más a los intereses de la entidad? Para encontrar la respuesta se deben saber los objetivos, el mercado meta y el tipo de contenido a compartir (Moya, 2014).

Pinterest a pesar de ser relativamente nueva y de que existen otras redes sociales con más usuarios como Facebook y Twitter, es considerada una de las redes sociales más idóneas para realizar marketing y concretar ventas (Fondevila et al., 2013). Por otro lado, destaca la intrusión e irritación que produce en los usuarios las publicaciones por parte de las empresas en las redes sociales comunes (Sicilia et al., 2016), a diferencia de lo que ocurre con Pinterest. Es por esto que a continuación se profundizará en esta red social. 


\subsection{Pinterest}

Pinterest "es una red social que consiste en un tablero virtual donde se pueden coleccionar y ordenar las cosas de la web que le gusten a cada usuario" (González, 2013). El nombre Pinterest viene del verbo en inglés Pin que significa colgar y el sustantivo "interest", el cual quiere decir interés, por lo que el concepto podría traducirse como 'colgar intereses' (González, 2013). Pinterest es un gran tablero en el cual se puede recopilar todo aquello que parezca interesante. Se puede coleccionar, compartir y organizar los diferentes intereses de cada persona. La idea de que sea un tablero virtual, nace de la inspiración de los tableros de corcho que se utilizan generalmente para poner información relevante o imágenes que gusten, en donde se pueden poner con alfileres post-its, notas, fotos, tarjetas y todo aquello que se quiera recordar o guardar, por lo que la idea de esta red social es crear los propios tableros temáticos de cada individuo (González, 2013). De esta forma, cada persona guarda en su perfil álbumes (en adelante tableros) de imágenes (pines) con sus intereses, ordenados por categorías creadas por cada usuario.

Se ha determinado que el público de Pinterest es básicamente femenino y se sitúa entre los 25 y 44 años. El nivel de estudio predominante es universitario y el nivel adquisitivo de renta media-alta (Fondevila et al., 2013). Además, los estudios dan a conocer que en promedio cada persona permanece alrededor de 16 minutos diarios en la red (González, 2013). Actualmente se puede acceder a Pinterest tanto a través del navegador como a través de la aplicación para dispositivos móviles.

\subsubsection{Características y funcionamiento de Pinterest}

Al igual que en otras redes sociales, Pinterest ofrece la posibilidad de crear un perfil personal. Al momento de registrarse, el sitio solicita seleccionar 5 temas para que las imágenes que se muestren en la página principal sean del interés de cada persona y ésta comience a interactuar en la red. Además de interactuar con sus 
intereses personales, cada usuario puede interactuar y visualizar pines de otras personas, siguiendo sus perfiles y por lo tanto, todos sus tableros o sólo algunos de ellos, dependiendo de la preferencia de cada pineador. Todos los usuarios de Pinterest poseen el nombre de "pineadores". Los usuarios que siguen los perfiles o tableros de otros son llamados seguidores y aquellos a los que el usuario sigue aparecen como seguidos. Para poder interactuar con los demás usuarios de Pinterest, en el feed de inicio (primera página que se muestra cuando se ingresa a Pinterest) aparecen los pines de las personas a las cuales se sigue o aquellos que pertenezcan a los intereses seguidos por el usuario. Además, en el feed de inicio aparece un buscador, donde se escriben palabras claves, para encontrar temáticas, pineadores o tableros del tema buscado.

Los individuos pueden realizar las siguientes acciones en Pinterest:

- Pinear: Cada usuario puede guardar en su perfil los contenidos que le gusten o le interesen, a esta acción se le denomina "pinear", puesto que hace referencia al hecho de colgar en un mural algo de interés sujetado con un alfiler (pin). Hay tres formas de hacer un pin: una de ellas es guardar una imagen que provenga del perfil de otro usuario o se encuentre en el feed de inicio (repin). La segunda es guardar una imagen que provenga de un sitio web y que ilustra el contenido que posee el sitio, y la tercera forma es guardar una imagen que no necesariamente fue sacada de un sitio y que el usuario sube sin ningún enlace, es decir, una foto o imagen personal. Para guardar los pines en su perfil, el usuario debe crear tableros y darles un nombre de acuerdo a la clasificación temática o categoría de los pines que desee guardar. Al pasar el cursor por el pin (versión web), o mantener el dedo sobre él (versión móvil) aparecen los botones que permiten realizar distintas acciones. Los botones son "Guardar", "Me gusta", "Enviar", "Ocultar" y "Visitar".

- Guardar o repin: Con esto se podrá replicar el pin que se ha encontrado y se podrá guardar en el tablero que se desee. A la acción antes descrita se le denomina repin. Al guardarlo no se perderá el recorrido o la procedencia del pin, 
por lo que se podrá saber quién subió la imagen a Pinterest. El repin es uno de los métodos más usados para guardar pines, de hecho, alrededor del $80 \%$ de los individuos perteneciente a la red social hace repin al contenido (González, 2013). Esta es una de las características del comportamiento de los usuarios en Pinterest, ya que la actividad no parece orientada a otros, dado que en su mayor parte, los usuarios no interactúan entre sí, sino más bien lo hacen con ellos mismos, por lo que se dice que es una red social no tan social (Phillips et al., 2014).

- "Me gusta": Al hacer clic en éste sólo se indica que el pin le gustó al usuario, ya que no se almacenará en ningún tablero, pero sí quedará un registro de todos los pines a los que se ha dado me gusta, en el perfil de cada pineador.

- "Enviar": Este botón permite compartir el pin vía mensaje, de forma interna a un seguidor o seguido, o compartirlo en otras redes sociales como Facebook, Twitter y Facebook Messenger, o bien proporcionar la dirección web de la imagen.

- "Ocultar": Éste y permite denunciar el pin, es decir, le permite al usuario indicar que el pin es plagio, no le gusta, no corresponde a la categoría, etc.

- "Comentar": Pinterest también permite escribir cualquier observación debajo del pin. A diferencia de otras redes sociales existe un muy bajo porcentaje de personas que realizan esta acción, ya que sólo el 0,6\% de los pines se comentan (González, 2013).

- "Visitar": Este botón sirve para entrar a un enlace externo a Pinterest desde el cual proviene la imagen. El sitio al que se redirecciona puede ser un artículo, un blog, una página web, un catálogo, etc.

- "Pin-It": Por último, existe un botón llamado "Pin It", el cual se encuentra en el navegador y facilita convertir el contenido del sitio web en un pin. Existe la opción de agregar este botón a la barra de favoritos de los navegadores, esto ayuda a los usuarios a recolectar pines de manera más sencilla. Este botón también lo pueden incorporar las empresas en sus páginas web, de esta forma facilitan a los usuarios guardar contenido en Pinterest desde los sitios web que agreguen ese botón. 
Por las características mencionadas con anterioridad podemos decir que los internautas se han vuelto fieles a esta red social, ya que ven contenido que realmente les interesa y pueden guardar sus ideas o aspiraciones en sus tableros. Además, es considerada la red social del futuro y los usuarios la aceptan tal cual es, porque está ligada a las aspiraciones que tienen, es decir, que pueden soñar en esta red social con todo aquello que les gustaría ver, tener o probar (González, 2013). El gusto de las personas por esta red social se justifica debido a que el usuario no ve cosas o situaciones que le desagraden o molesten, como por ejemplo, que los demás usuarios expongan sus vidas privadas o que haya exceso de publicidad o intrusión de las marcas en lo que consideran un espacio personal (González, 2013). Es por esto que se crea fidelización del usuario hacia Pinterest y en el buen sentido de la palabra, adicción (González, 2013). Este último punto es una de las diferencias que se pueden apreciar entre Pinterest y otras redes sociales hasta el momento.

\subsubsection{Pinterest como herramienta de marketing}

Aunque Pinterest sólo vende publicidad a través de "pines patrocinados" para las empresas de EE.UU, Canadá y el Reino Unido, las empresas pueden usarla para canalizar el marketing a través de ella. Pueden crear un perfil corporativo o transformar uno personal en un perfil de marca. Al crear este tipo de perfil, la empresa puede añadir una descripción de la cuenta para mostrarse al público y subir imágenes a sus tableros con una breve descripción de estos últimos, donde pueden poner enlaces a otros sitios de la web, como por ejemplo sus catálogos de productos o sus sitios web corporativos.

Pinterest funciona como una herramienta comunicacional, es un puente que permite el tráfico a la web de origen y facilita la concreción de ventas. Las empresas interactúan con los usuarios o potenciales clientes como un internauta más, lo cual permite averiguar cómo estos se relacionan con su marca o productos. Por lo tanto, en la red social se puede inducir a la compra, pero donde se concretará es en el sitio web de procedencia del pin, a través del hipervínculo 
que se encuentra inserto en la imagen subida a Pinterest (Fondevila et al., 2013). Además, se pone a disposición el botón Pin It, el cual propicia que la empresa entregue a su público los enlaces a sus sitios externos a través de los pines que publica. Entonces, dadas sus características, Pinterest puede impulsar las compras online, puesto que actúa como nexo entre los usuarios y las tiendas virtuales, fomentando el comercio electrónico (Fondevila et al., 2013). Esto se refleja en que el $32 \%$ de compradores norteamericanos online han realizado alguna compra como resultado de haber visualizado una imagen en una red social visual (Fondevila et al., 2013).

Si se evalúa a Pinterest como medio para canalizar acciones de marketing, es una de las redes sociales más deseables y convenientes puesto que es idónea para presentar la empresa con una imagen clara, sencilla y amigable. Además, los usuarios de Pinterest son más propensos a seguir comercios que los usuarios de otras redes sociales, así lo confirma el estudio de Fondevila et al. (2013), el cual determinó que los consumidores online seguían una media de 9,3 perfiles corporativos en Pinterest, 8,5 en Twitter y 6,9 en Facebook. Se puede afirmar entonces que Pinterest se proyecta como una buena herramienta de marketing, pero se debe usar con astucia y entender la esencia de ella para lograr el éxito e influenciar de manera positiva a los consumidores. Así lo confirma Fondevila et al. (2013) que determinó que Pinterest es capaz de influir en las decisiones de compra del $47 \%$ del público femenino en Estados Unidos, una cifra mayor de lo que logran Facebook y Twitter. Las empresas pueden fomentar la utilización de la red social por parte de sus seguidores realizando concursos o enviándoles emails desde la propia plataforma.

Aunque ya se está creando conciencia de la utilidad de Pinterest y la necesidad de sacar el máximo provecho de ella por parte de las firmas, aún no hay ningún estudio que entregue recomendaciones para que las empresas optimicen el uso de esta red social. Se han propuesto consejos en base a observación, y de carácter intuitivo, porque no están validados por ningún estudio, o bien la 
metodología usada para dicha investigación no ha incluido la experiencia del usuario de Pinterest y, por lo tanto, no se sabe el efecto que tienen las acciones realizadas por las empresas en la red social y si éstas son realmente efectivas. Por otro lado, los estudios más determinantes que existen se han realizado para Europa y Estados Unidos, por lo que no hay datos disponibles para Latinoamérica y Chile. Esto justifica la importancia de realizar un estudio que explique el comportamiento del consumidor chileno en Pinterest para conocer cómo la empresa puede utilizar esta red social de una manera efectiva. Por lo tanto, proponemos las siguientes preguntas de investigación:

Pregunta de investigación 1: ¿Cómo utilizan los consumidores chilenos la red social Pinterest?

Pregunta de investigación 2: ¿Cómo perciben los consumidores chilenos las acciones que realizan las empresas en Pinterest?

\section{METODOLOGÍA}

El público objetivo del estudio lo forman hombres y mujeres, de cualquier edad, que fuesen usuarios de Pinterest y que vivieran en Chile. El instrumento que se diseñó para realizar la investigación fue una encuesta online en la que se aplicó una pregunta filtro para asegurarse de que el encuestado perteneciera al universo estudiado, en la cual se le preguntó si era usuario de Pinterest. Si su respuesta era negativa automáticamente finalizaba la encuesta. Para medir su intención de compra de productos que ha visto en la red social se usaron escalas de tipo Likert de 7 puntos. En el estudio se adaptaron escalas utilizadas previamente en otros estudios, como vemos en la Tabla 1. 
Tabla 1: Variables usadas en el estudio

\begin{tabular}{|c|c|c|c|}
\hline Variable & Escala & $\begin{array}{l}\text { Tipo de } \\
\text { Escala }\end{array}$ & Fuente \\
\hline \multirow{2}{*}{$\begin{array}{l}\text { Intención de } \\
\text { Compra de } \\
\text { productos que } \\
\text { ha visto en } \\
\text { Pinterest }\end{array}$} & $\begin{array}{l}\text { Probablemente elegiré uno de los } \\
\text { productos que veo en Pinterest }\end{array}$ & \multirow{2}{*}{$\begin{array}{l}\text { Likert de } 7 \\
\text { puntos }\end{array}$} & \multirow{2}{*}{$\begin{array}{l}\text { Zhang y Buda } \\
\text { (1999) }\end{array}$} \\
\hline & $\begin{array}{l}\text { Es posible que compre un producto que } \\
\text { he visto en Pinterest }\end{array}$ & & \\
\hline \multirow{2}{*}{$\begin{array}{l}\text { Intención de } \\
\text { Compra de } \\
\text { productos que } \\
\text { ha guardado en } \\
\text { su tablero }\end{array}$} & $\begin{array}{l}\text { Probablemente elegiré uno de los } \\
\text { productos que guarde en mi tablero }\end{array}$ & \multirow{2}{*}{$\begin{array}{l}\text { Likert de } 7 \\
\text { puntos }\end{array}$} & \multirow{2}{*}{$\begin{array}{l}\text { Zhang y Buda } \\
\text { (1999) }\end{array}$} \\
\hline & $\begin{array}{l}\text { Guardo en mis tableros los productos } \\
\text { que me gustaría comprar }\end{array}$ & & \\
\hline
\end{tabular}

Por otro lado, dado que no se encontraron escalas que se pudieran usar para obtener información acerca del uso de Pinterest, se crearon preguntas que tenían directa relación con Pinterest, sus características propias y las acciones que se realizan en esta red social con base en el marco teórico desarrollado. En la Tabla 2 se resumen las preguntas que se encuentran bajo estas condiciones. Las últimas preguntas del cuestionario hacían referencia a aspectos sociodemográficos como edad, género, lugar de residencia e ingresos.

La encuesta se realizó vía online cuyo link se compartió a través de Facebook a las personas que se tenía conocimiento que utilizaban la red social estudiada. Además, en Pinterest se creó un tablero en el cual se compartía el enlace de la encuesta en una serie de pines dentro de dicho tablero. Por otro lado, se buscaron perfiles de empresas chilenas en la red social y se envió un mensaje interno a los seguidores de esas empresas, adjuntando el link de la encuesta y explicando de qué se trataba, a quienes se dirigía y solicitando compartir el link con otros usuarios de Pinterest que ellos conocieran. Este procedimiento ha sido utilizado previamente en otros estudios (Por ejemplo, De Bruyn \& Lilien (2008)).

El total de encuestas recolectadas fueron 171, de las cuales solo se utilizaron 139 para los diversos análisis, debido a que se usaron solamente aquellas encuestas 
que respondían sí a la pregunta filtro (usuarios que utilizaban Pinterest) y que pertenecieran a personas que viven en Chile.

Tabla 2: Preguntas creadas en base al marco teórico

\begin{tabular}{|c|c|c|}
\hline $\begin{array}{l}\text { Acciones } \\
\text { en Pinterest }\end{array}$ & Preguntas del cuestionario & $\begin{array}{l}\text { Tipo de } \\
\text { escala }\end{array}$ \\
\hline \multirow{3}{*}{$\begin{array}{l}\text { Guardar o } \\
\text { repin }\end{array}$} & Suelo guardar imágenes en mis tableros desde perfiles de otros usuarios (repin) & \multirow{3}{*}{$\begin{array}{l}\text { Likert de } \\
7 \text { puntos }\end{array}$} \\
\hline & Suelo guardar imágenes en mis tableros desde la galería de mis dispositivos & \\
\hline & Solo guardo imágenes en los tableros y luego no las veo & \\
\hline Me gusta & Suelo darle me gusta a los pines que me llaman la atención & $\begin{array}{l}\text { Likert de } \\
7 \text { puntos }\end{array}$ \\
\hline Enviar & $\begin{array}{l}\text { Suelo enviar algún Pin a través de las opciones que ofrece Pinterest (email, } \\
\text { Facebook, Whatsapp, etc) }\end{array}$ & $\begin{array}{l}\text { Likert de } \\
7 \text { puntos }\end{array}$ \\
\hline Comentar & Suelo comentar los Pines & $\begin{array}{l}\text { Likert de } \\
7 \text { puntos }\end{array}$ \\
\hline \multirow{3}{*}{ Visitar } & Suelo visitar los perfiles de las empresas o marcas que sigo & \multirow{3}{*}{$\begin{array}{l}\text { Likert de } \\
7 \text { puntos }\end{array}$} \\
\hline & $\begin{array}{l}\text { Suelo visitar sitios webs de empresas a través de los enlaces disponibles en los } \\
\text { Pines (imágenes) }\end{array}$ & \\
\hline & $\begin{array}{l}\text { Me gusta que las imágenes de Pinterest usen el botón "Visitar" para dirigirme a sus } \\
\text { catálogos de productos }\end{array}$ & \\
\hline Pin-it & Suelo guardar imágenes en mis tableros desde la web (botón Pin it) & $\begin{array}{l}\text { Likert de } \\
7 \text { puntos }\end{array}$ \\
\hline \multirow{4}{*}{$\begin{array}{l}\text { Búsqueda de } \\
\text { información }\end{array}$} & Busco información en Pinterest de productos que deseo adquirir & \multirow{4}{*}{$\begin{array}{l}\text { Likert de } \\
7 \text { puntos }\end{array}$} \\
\hline & Busco información en Pinterest de cómo usar los productos que tengo o deseo tener & \\
\hline & Busco información o ideas en Pinterest de proyectos que deseo concretar & \\
\hline & Busco información de un tema en específico en el feed de inicio & \\
\hline \multirow{3}{*}{$\begin{array}{c}\text { Acciones de la } \\
\text { empresa en } \\
\text { Pinterest }\end{array}$} & Me molesta que las empresas sigan mi perfil en Pinterest & \multirow{3}{*}{$\begin{array}{l}\text { Likert de } \\
7 \text { puntos }\end{array}$} \\
\hline & $\begin{array}{l}\text { Participaría de algún concurso o actividad propuesta por alguna empresa en } \\
\text { Pinterest }\end{array}$ & \\
\hline & Me gustaría recibir email de las empresas para visitar sus pines o tableros & \\
\hline
\end{tabular}

\section{RESULTADOS}

\subsection{Características demográficas de la muestra}

El $81 \%$ de las personas que respondieron la encuesta fueron mujeres y el $19 \%$ restante corresponde a hombres; de los cuales, la mayoría (27\%) reside en Santiago, 17\% vive en La Serena, 16\% de Coquimbo y las personas restantes pertenecen a diversas ciudades del país tales como Antofagasta, Arica, Calama, 
Rancagua, o Concepción. En cuanto a la ocupación de las personas, destacan los estudiantes los cuales corresponden al $42 \%$ y los trabajadores dependientes los cuales alcanzaron un 40\%. Esto concuerda con los niveles de ingresos declarados por los encuestados, donde el $45 \%$ de las personas percibe un ingreso inferior a $\$ 265.000$ y la segunda mayoría (20\%) gana mensualmente entre $\$ 265.000$ y $\$ 550.000$. Por su parte, la media de la edad de las personas encuestadas es de 29 años.

\subsection{Características de los usuarios con respecto a la red social}

En el Gráfico 1 se muestra la frecuencia con la que los usuarios ingresan a la red social en porcentajes, donde se observa que más de un tercio de los usuarios que forman la muestra visita Pinterest todos los días, mientras que el $20 \%$ lo hace cada dos días. Sólo el $4 \%$ de los usuarios visita la red social menos de dos veces al mes, lo que indica que la mayoría de las personas activas en Pinterest la visita con regularidad.

El Gráfico 2 muestra la cantidad de minutos que permanece cada usuario en Pinterest cada vez que ingresa a la misma. Se puede observar que el rango de tiempo de visita es muy amplio, ya que hay usuarios que solo visitan Pinterest por 2 minutos mientras que otros permanecen hasta 3 horas navegando en ella, aunque son pocos los usuarios que se ubican en ambos extremos, siendo la visita más común de 30 minutos. Cabe destacar que en promedio las personas navegan 36 minutos en la red social en cada una de sus visitas. 
Gráfico 1: Frecuencia de visita de los usuarios de Pinterest a la red social

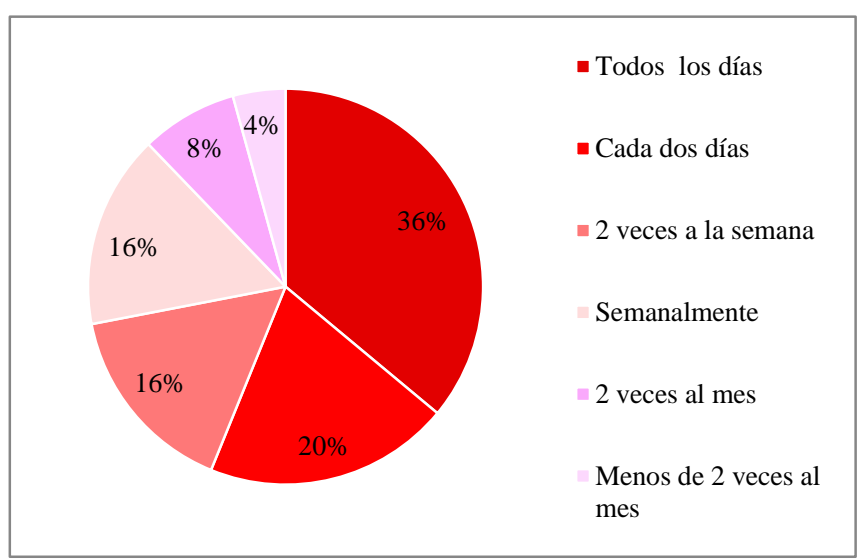

Gráfico 2: Tiempo de permanencia de los usuarios en Pinterest

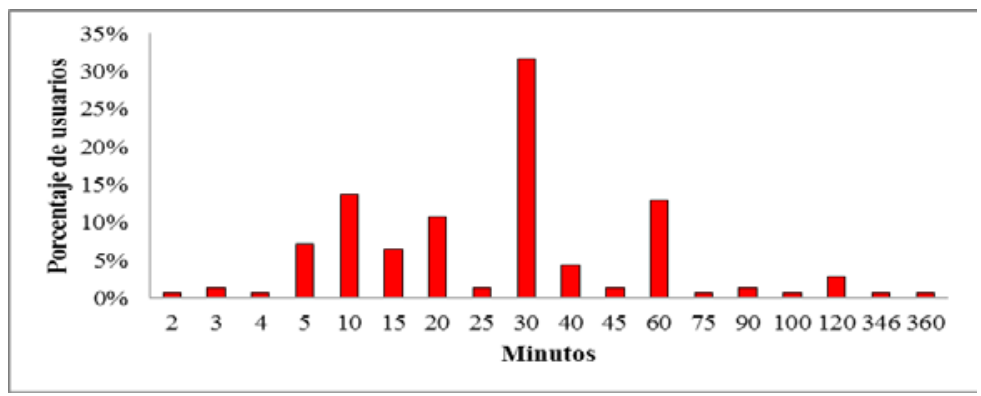

Por otro lado, como podemos apreciar en el Gráfico 3, la cantidad de tableros que tiene cada uno de los usuarios de Pinterest varía bastante, hay personas que no tienen ninguno y que solo navegan y le dan a "Me gusta" a los pines que les llaman la atención, como hay otras que tienen gran cantidad de ellos, pero la mayoría se encuentra entre 2 y 15 tableros por perfil, siendo la media de 14 tableros.

Gráfico 3: Número de tableros por usuario

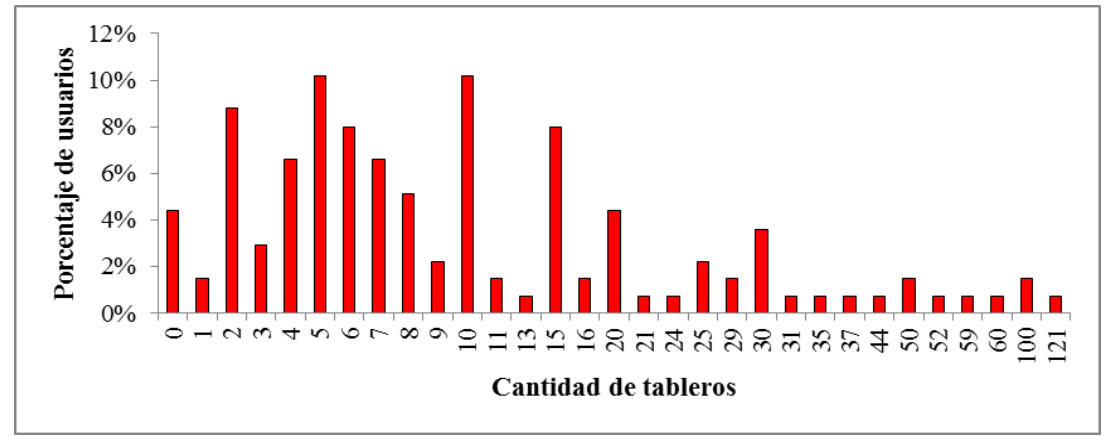

REDMARKA IMARKA-Universidad de A Coruña - CIECID Año XI, Número 20, (2018), vol. 1 pp. 201-229 http://www.redmarka.net/ ISSN 1852-2300 
El Gráfico 4 representa el número de perfiles de empresas que siguen los usuarios de la muestra. Destacar que el 30,1\% de los encuestados no siguen el perfil de ninguna empresa. El rango de empresas seguidas va desde 0 hasta 100, mientras que la media asciende a 10 empresas seguidas por cada usuario.

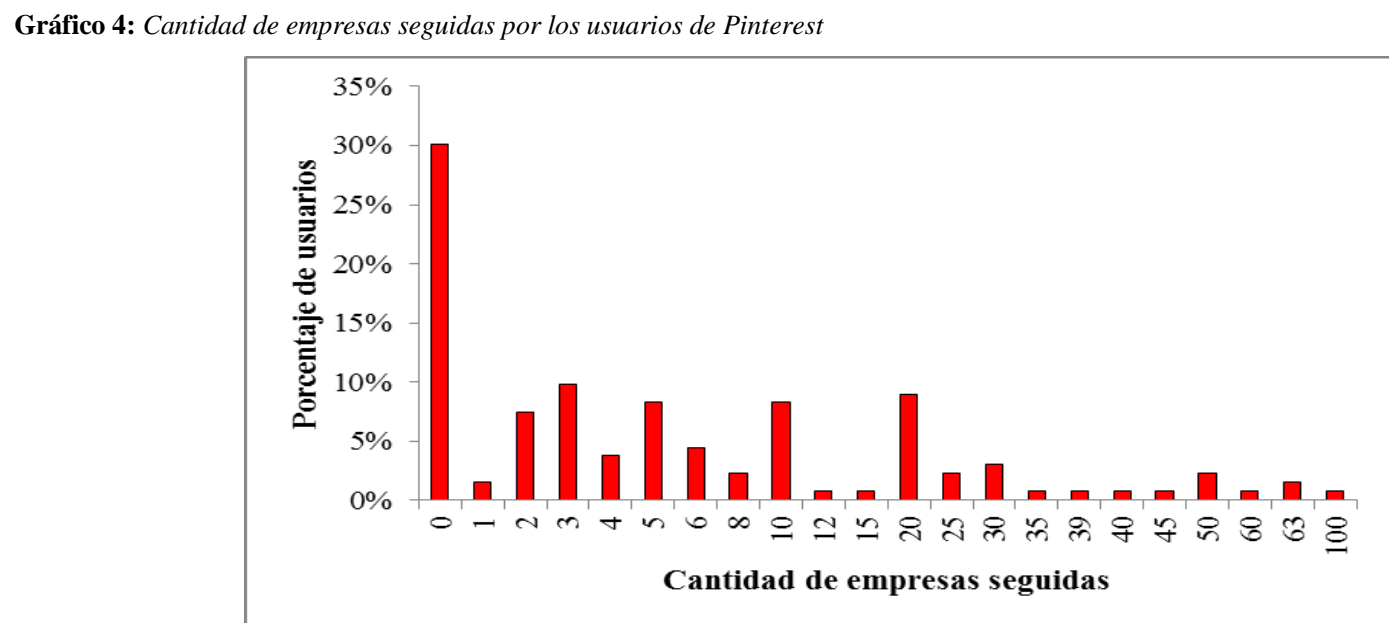

Por otro lado, el estudio arrojó que tan sólo el 37\% de los encuestados era seguido por alguna empresa en Pinterest, lo que indica que las empresas no están usando esta función o bien que las personas no son conscientes de quienes los siguen, dado que en Pinterest no se necesita la aprobación de la persona para seguir su perfil. Con respecto a las temáticas más populares seguidas por los usuarios de la muestra, en el Gráfico 5 se observa que el $61 \%$ de las personas aseguró que seguía los pines acerca de Vestuario y un 50\% indicó que seguía pines de Decoración. Cabe mencionar que dentro de la temática "Otros", se encuentran todas aquellas alternativas propuestas que reunían un menor porcentaje de las preferencias y a su vez aquellas temáticas expresadas por cada usuario, las cuales no se podían clasificar en ninguna categoría y eran muy numerosas, como por ejemplo salud, autos, historia y religión, entre otros. 
Gráfico 5: Temáticas seguidas por los usuarios en Pinterest

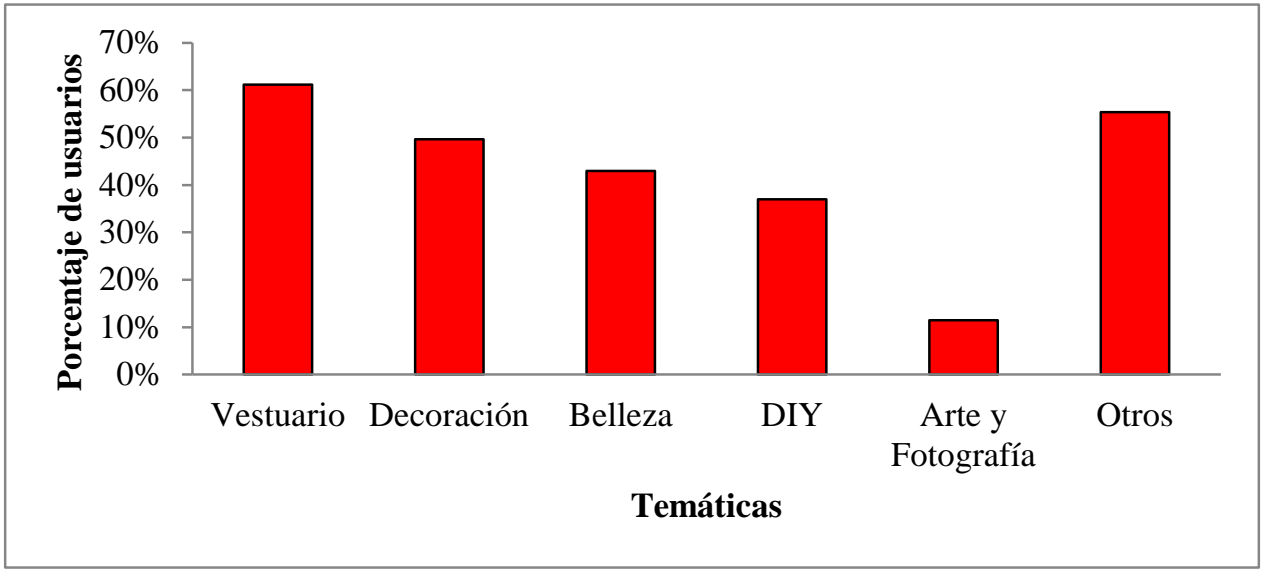

Nota 1: los porcentajes mostrados corresponden a una pregunta de selección múltiple, por lo tanto, no suman 100\%.

Nota 2: DIY del inglés Do It Yourself, es decir, proyectos de Hágalo usted mismo.

\subsection{Fiabilidad de las escalas}

En el presente estudio se utilizaron dos escalas adaptadas de estudios anteriores, con las cuales se midió la intención de compra tanto de los productos vistos en Pinterest como los guardados en los tableros. Tanto las escalas de intención de comprar los productos vistos en Pinterest ( $\alpha$-Crombach=0,943) como la de intención de comprar productos en los tableros ( $\alpha$-Crombach $=0,932)$ cumplen los criterios de fiabilidad (Nunnally, 1978).

\subsection{Análisis de las funciones de Pinterest}

A continuación, se mostrará los resultados que se obtuvieron acerca de las distintas acciones que pueden realizar los usuarios de Pinterest en la red social. Además, se muestran análisis adicionales que resultaron significativos para determinar si existían diferencias en los resultados dependiendo de la edad y el género de los usuarios.

\section{a. Función "Guardar"}

Como se aprecia en la Tabla 3, según las medias calculadas para estas variables, es más común que los usuarios de la red social guarden las imágenes 
desde perfiles de otros usuarios de Pinterest (repin) y a través del botón Pin It (desde la web). Se realizó una prueba T-student para muestras relacionadas, la cual mostró que estas medias no son significativamente diferentes, por ende, se puede afirmar que los usuarios de Pinterest suelen guardar imágenes con la misma frecuencia desde la web y desde el perfil de otros usuarios. Por otro lado, se puede afirmar que lo que menos hacen los usuarios es guardar pines desde sus dispositivos, es decir, prefieren guardar en sus tableros imágenes de otros usuarios o de la web que imágenes personales o de autoría propia.

Tabla 3: Media de las variables Guardar

\begin{tabular}{|l|l|}
\hline \multicolumn{2}{|c|}{ Variables } \\
\hline Suelo guardar imágenes en mis tableros desde perfiles de otros usuarios (repin) \\
\hline Suelo guardar imágenes en mis tableros desde la web (botón Pin it) \\
\hline Suelo guardar imágenes en mis tableros desde la galería de mis dispositivos (imágenes personales) \\
\hline
\end{tabular}

Nota: Las medias con diferente superíndice son significativamente diferentes $(\mathrm{p}<0.05)$ según prueba T-student para muestras relacionadas

Cabe destacar que la respuesta de los encuestados que tienen tableros a la afirmación "Suelo guardar imágenes en los tableros y luego no las veo", tiene una media de 2,78 en una escala donde 1 corresponde a "Muy en desacuerdo" y 7 a "Muy de acuerdo". De este resultado se interpreta que los usuarios en Pinterest suelen revisar los pines que han guardado con posterioridad y no los guardan sin razón.

b. Funciones de Interacción con el Pin (Me gusta, Repin, Enviar y Comentar) Al observar la Tabla 4 notamos que la mayor media entre las acciones que un usuario puede realizar con los pines corresponde a la de darle a "Me gusta" al pin y la segunda mayor media corresponde a la acción repin. Según los análisis de esta investigación lo más conveniente para la empresa es que el usuario repinee sus imágenes en la red social ya que de esta forma los usuarios lo guardan en sus tableros y luego vuelven a verlas, pero a su vez también es ventajoso que el usuario le dé a "Me gusta" al pin ya que como se menciona en el marco teórico, se guarda un registro en el perfil de cada usuario. 
Tabla 4: Media de las variables interacción con los pines

\begin{tabular}{|l|c|}
\hline \multicolumn{1}{|c|}{ Variables } & Media \\
\hline Suelo darle me gusta a los pines que me llaman la atención & $4,58^{\mathrm{a}}$ \\
\hline $\begin{array}{l}\text { Suelo guardar imágenes en mis tableros desde perfiles de otros } \\
\text { usuarios (repin) }\end{array}$ & $4,02^{\mathrm{b}}$ \\
\hline $\begin{array}{l}\text { Suelo enviar pines a través de las opciones que ofrece Pinterest } \\
\text { (email, Facebook, Whatsapp, etc) }\end{array}$ & $2,66^{\mathrm{c}}$ \\
\hline Suelo comentar los Pines & $1,77^{\mathrm{d}}$ \\
\hline
\end{tabular}

Nota: Las medias con diferente superíndice son significativamente diferentes $(\mathrm{p}<0.05)$ según prueba T-student para muestras relacionadas

Las otras dos acciones, correspondientes a "Enviar" y "Comentar" los pines aparecen con valoraciones muy bajas según los encuestados. Se podría decir entonces que lo que hacen los usuarios con más frecuencia es darle a "Me gusta" a los pines que más les llaman la atención y hacer repin, sin embargo, no suelen comentarlos o compartirlos con sus contactos a través de las opciones disponibles. Además, se confirma esta conclusión con los datos aportados por la prueba T-Student donde se observa que los valores medios de las acciones estudiadas son significativamente diferentes $(p<0.05)$.

\section{c. Función "Visitar"}

En la Tabla 5 se muestra la información de las variables relacionadas con la función "Visitar" ofrecida por Pinterest. Se observa que ambas medias se encuentran muy cercanas y están por debajo de la mitad de la escala de valoración propuesta (de 1 a 7), lo que indica que las personas no visitan con frecuencia los perfiles de las empresas en Pinterest y los sitios web de las mismas a través del enlace del pin. Además, según la prueba T-Student se observa que las medias de las variables estudiadas no son significativamente distintas entre sí.

Tabla 5: Prueba de muestras relacionadas variables de visita

\begin{tabular}{|l|c|c|c|}
\hline \multicolumn{1}{|c|}{ Variables } & Media & T & $\begin{array}{c}\text { Sig. } \\
\text { (bilateral) }\end{array}$ \\
\hline \hline Suelo visitar los perfiles de las empresas o marcas que sigo & 3,13 & & \\
\hline $\begin{array}{l}\text { Suelo visitar sitios webs de empresas a través de los enlaces } \\
\text { disponibles en los Pines (imágenes) }\end{array}$ & 3,04 &, 687 \\
\hline
\end{tabular}


Cabe destacar que según la encuesta realizada, a las personas les gustaría que las empresas usen el botón "Visitar" para dirigirse a los catálogos de productos, ya que la media es de 4,05 en una escala de 1 a 7 .

\section{d. Búsqueda de información en Pinterest}

Según lo que muestra la Tabla 6, lo que los usuarios más buscan en la red social es información de proyectos que desean concretar, mientras que lo que menos buscan es información de productos que desean adquirir, aunque no es una media baja $(3,96)$, ya que se encuentra por sobre la mitad de la escala de evaluación de 1 a 7 . A pesar de que las medias parecen estar cercanas, observamos que al compararlas entre sí, son todas significativamente distintas unas de otras.

Tabla 6: Medias de las variables de búsqueda de información

\begin{tabular}{|l|c|}
\hline \multicolumn{1}{|c|}{ Variables } & Media \\
\hline $\begin{array}{l}\text { Busco información o ideas en Pinterest de proyectos que } \\
\text { deseo concretar. }\end{array}$ & $5,2^{\mathrm{a}}$ \\
\hline $\begin{array}{l}\text { Busco información de un tema en específico en el feed de } \\
\text { inicio }\end{array}$ & $4,86^{\mathrm{b}}$ \\
\hline $\begin{array}{l}\text { Busco información en Pinterest de cómo usar los productos } \\
\text { que tengo o deseo tener }\end{array}$ & $4,37^{\mathrm{c}}$ \\
\hline $\begin{array}{l}\text { Busco información en Pinterest de productos que deseo } \\
\text { adquirir }\end{array}$ & $3,96^{\mathrm{d}}$ \\
\hline
\end{tabular}

Nota: Las medias con diferente superíndice son significativamente diferentes $(\mathrm{p}<0.05)$ según prueba T-student para muestras relacionadas

\subsection{Análisis de las acciones de las empresas}

\section{a. Seguir a los consumidores}

Según los análisis realizados, a las personas no les molesta que las empresas sigan su perfil, ya que en una escala de desagrado de 1 a 7, la media fue de 2,04. Además, se realizó una prueba Anova de un factor para comprobar a quienes les molesta más que les sigan las empresas, a aquellos que ya les siguen o a aquellos usuarios a los que todavía no les sigue ninguna empresa. De este análisis se concluye que a quienes no les siguen las empresas les molestaría más 
que los siguieran que a aquellas personas que si les siguen $\left(X_{\text {no le siguen }}=2,3 \mathrm{vs}\right.$. $X_{l e}$ siguen=1.59; $\mathrm{F}=6.494 ; p<0.05)$.

\section{b. Enviar email a los usuarios}

Según los análisis llevados a cabo, las personas no están interesadas en recibir email de las empresas para visitar sus tableros, ya que la media más alta, entre quienes han recibido este tipo de email y quienes no, es de 2,26 , en una escala de 1 a 7.

\section{c. Realizar concurso en Pinterest}

Otro de los análisis realizados tiene relación con los concursos llevados a cabo por las empresas en Pinterest, con el fin de determinar si éstos tienen una buena acogida por parte de los usuarios. En la Tabla 7 se muestra el contraste entre las variables "Ha visto alguna promoción, campaña o concurso en Pinterest" y "Ha participado en un concurso en Pinterest". Se observa que la gran mayoría de las personas encuestadas (78\%) no han visto y por lo tanto no han participado de alguna campaña en la red social, y de quienes han visto alguna campaña (22\%) sólo 4 personas han participado. Además, según el estadístico Chi-cuadrado, la diferencia entre quienes han visto campañas en Pinterest y quienes no, es significativa $\left(x^{2}=0,02 ; p<0,05\right)$. De este análisis se puede concluir que esta red social no es utilizada por las empresas de Chile para realizar concursos o campañas publicitarias, esto puede ser porque aún no tienen gran conocimiento de Pinterest o no han sacado el máximo provecho de esta red social. 
Tabla 7: Tabla de contingencia, ver y participar en campañas

\begin{tabular}{|l|c|c|c|c||}
\hline \multicolumn{1}{|l|}{} & \multicolumn{2}{|c|}{ Ha visto campaña } & \multirow{2}{*}{ Total } \\
\cline { 2 - 5 } \multicolumn{1}{|l|}{} & No & Sí & \\
\hline \multirow{2}{*}{$\begin{array}{l}\text { Ha participado en } \\
\text { concurso }\end{array}$} & No & $78 \%$ & $19 \%$ & $97 \%$ \\
\cline { 2 - 5 } & Sí & $0 \%$ & $3 \%$ & $3 \%$ \\
\hline \hline Total & $78 \%$ & $22 \%$ & $100 \%$ \\
\hline
\end{tabular}

Al analizar por separado las medias de la afirmación "Participaría de algún concurso o actividad propuesta por alguna empresa en Pinterest" para quienes han participado de concursos y quienes no, resultó que quienes sí han participado tuvieron una media de respuesta de 6,5 a la afirmación, mientras que quienes no lo habían hecho tuvieron una media de 3,35. Aunque no se cuenta con datos suficientes para realizar análisis estadísticamente correctos, estas medias nos hacen intuir que quienes ya han participado de algún concurso o actividad propuesta por alguna empresa estarían dispuestos a volver a hacerlo y quienes no tienen una menor disposición.

\subsection{Análisis de la intención de compra y adquisición de productos}

a. Intención de compra

La Tabla 8 representa la media de la intención de compra tanto de los productos vistos como de los guardados en la red social, siendo estos últimos los de mayor media $(4,4)$ en una escala del 1 al 7 , es decir es más probable que una persona compre los productos que ha guardado en sus tableros en comparación con los que sólo ha visto en la red social, esta conclusión es confirmada con la Prueba T para muestras relacionadas donde el valor $p$ es menor a 0,05 . 
Tabla 8: Medias de las variables de intención de compra

\begin{tabular}{|l|c|c|c||}
\hline \multicolumn{1}{|c|}{ Variables } & Media & $\mathrm{t}$ & $\begin{array}{c}\text { Sig. } \\
\text { (bilateral) }\end{array}$ \\
\hline \begin{tabular}{l|l|l||}
\hline Intención de compra de productos guardados en \\
los tableros
\end{tabular} & 4,4 & \\
\hline \hline Intención de compra de productos vistos & 4,03 & $-5,686$ & \\
\hline
\end{tabular}

b. Productos vistos en Pinterest y adquiridos por los usuarios

Según los datos de la encuesta, del total de 139 personas, sólo $20 \%$ de ellas han adquirido un producto que han visto en la red social. De estas últimas, 25\% ha adquirido 2 productos, el $18 \% 5$ productos y un $4 \%$ ha adquirido 25 productos, como se aprecia en el Gráfico 6 . En media, quienes han comprado productos vistos en Pinterest, han adquirido 5 productos.

El Gráfico 7 muestra cuantos de los productos que los usuarios han adquirido los tenían guardados en sus tableros. Cabe destacar que el $94 \%$ de los productos que han sido comprados luego de ser vistos en Pinterest estaban guardados en los tableros de los usuarios.

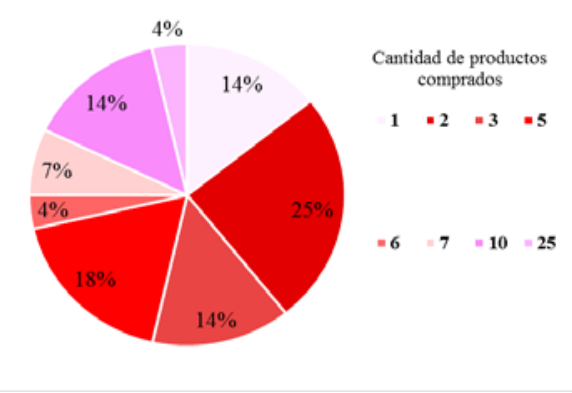




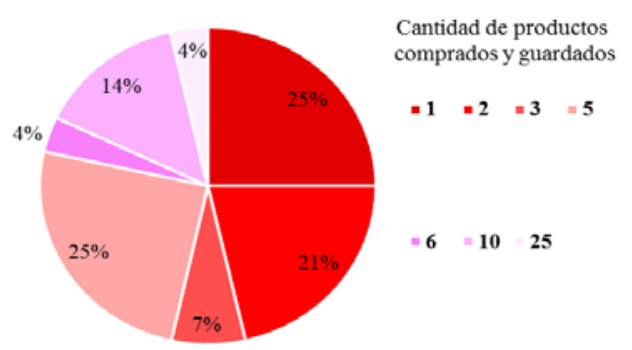

\section{CONCLUSIONES}

Pinterest es una red social que a diferencia de las demás no es usada masivamente por los chilenos, como es el caso de Facebook y Twitter, sino más bien es utilizada por personas que buscan ideas para sus proyectos y pasatiempos o información de sus intereses. Al ser una red social visual resulta ser idónea para realizar estrategias de marketing. Además, a las personas no se les abruma, ya que éstas visualizan solo aquellas cosas que les interesan. Esta red social es muy útil para las empresas ya que es capaz de generar un nexo entre éstas y el cliente e incluso inducir a la compra, pero para lograrlo la empresa debe tener siempre presente la naturaleza de Pinterest y la forma de usarla, ya que no funciona de la misma manera que las redes sociales más populares. Por lo que esta investigación tenía como objetivo analizar al usuario chileno de Pinterest y su percepción de las acciones realizadas por las empresas en esta red social.

Para lograr los objetivos propuestos en la investigación se realizó un estudio a nivel nacional, en el cual se le preguntó a los usuarios de la red social cuestiones acerca de su comportamiento y preferencias dentro de la misma, con lo cual se logró además perfilar a los usuarios chilenos e idear las estrategias para que las empresas usen Pinterest de manera correcta y logren sus objetivos al incluirla en su estrategia de marketing. A través de este estudio se pudo determinar que las 
personas buscaban información sobre todo acerca de ideas para sus proyectos futuros, de productos que querían adquirir e información acerca de cómo usar los mismos o los productos que ya tenían. Por otro lado, se descubrió que lo que más realizan los usuarios es dar a "Me gusta", repinear y usar el botón Pin It, lo cual es muy beneficioso para las empresas, dado que de todas las formas nombradas, los pines quedan en el perfil del cliente, y según los análisis realizados, los productos que están guardados en los tableros tienen una mayor intención de compra que los que sólo han visto en la red social, ya que estos los vuelven a ver un tiempo después. Además, al usar el botón Pin It los usuarios compartían información de las empresas en Pinterest lo que permitía que la misma llegara a más personas. Asimismo, se observó que las empresas en Chile no han realizado muchos concursos en Pinterest, pero las personas están dispuestas a participar en ellos, más aún los pocos que ya han participado tienen mayor disposición a volver a hacerlo, por lo que al no realizar concursos o campañas se está desaprovechando la oportunidad de lograr diversos objetivos usando esta estrategia.

A pesar de que Pinterest no se usa masivamente en Chile, hay que tener en cuenta que nos encontramos ante una red social de nicho cuyo uso puede ser muy beneficioso para las empresas que se dirijan al público que se encuentra en esta red social. La información que se entrega en esta investigación es útil para que las empresas que creen su perfil las tomen en cuenta, creen y logren interactuar con los usuarios, ya que sabrán cómo llegar a su público objetivo sin abrumarlo, y a lo largo de la utilización de Pinterest conocerán de mejor manera a sus usuarios y les permitirá descubrir lo que éstos quieren. Finalmente, cabe destacar que este estudio es el primero que se realiza formalmente en Chile, por lo que contribuye tanto a las investigaciones como a la práctica del Marketing online.

Este estudio también tiene sus limitaciones de las que se derivan futuras líneas para seguir ahondando en la investigación de Pinterest en Chile. Una de ellas es 
la muestra. El estudio utiliza una muestra de conveniencia de 139 personas, por lo que sus resultados los deberíamos tomar como una aproximación al conocimiento de la utilización de Pinterest por parte del consumidor chileno. Un estudio con una muestra más grande y obtenida de manera aleatoria nos permitiría conocer mejor este fenómeno. Además, sería interesante analizar más en profundidad qué acciones están realizando las empresas chilenas en esta red social.

\section{REFERENCIAS BIBLIOGRÁFICAS}

Barnes, N. (2014), "Social Commerce Emerges As Big Brands Position Themselves to Turn "Follows", "Likes" and "Pins" into Sales". American Journal of Management, 14 (4), pp. 11-18.

Catalyst \& Forrest Consulting (2016), "Customers rely on search \& social to find and choose products". EEUU: Catalyst y Forrest Consulting. Disponible en <http://www.catalystdigital.com/ > Último acceso: 13 de mayo de 2017.

Chow, W. S. \& Shi, S. (2015), "Investigating customers' satisfaction with brand page in social networking sites". Journal of Computer Information Systems, 55(2), pp. 48-58.

ComScore (2014) "El estado de social media en México". México: ComScore. Disponible en <http://www.comscore.com/ > Último acceso: 1 de abril de 2017.

De Bruyn, A. \& Lilien, G. L. (2008), "A multistage model of Word-of-mouth influence of viral marketing". International Journal of Research in Marketing, 25 (3), pp. 151-163.

EGM (2013). "Estudio general de medios". Chile: Ipsos. 2013. Disponible en <http://www.ipsos.com/ > Último acceso: 11 de abril de 2017. 
Fondevila, J., Herrando, C., Beriain A. \& del Olmo, J. (2013), "Social media and ecommerce electronic: Pinterest as a new communication tool". Doxa Comunicación: revista interdisciplinar de estudios de comunicación y ciencias sociales, 16 (1), pp. 151-172.

Global Web Index (2016), "Milleannials actively using 4+ social networks. 2016". Disponible en <http://www.globalwebindex.net/ > Último acceso: 20 de mayo de 2017.

González, M. M. A. (2013) "Pinterest: la red social visual y creativa". Barcelona, España: Editorial UOC.

Harris, L. \& Rae, A. (2009), "Social networks: The future of marketing for small business". The Journal of Business Strategy, 30(5), pp. 24-31.

Hogan, B. (2008), "Analyzing social networks via the internet". En N. Fielding, R. Lee \& G. Blank (Eds.), Sage Handbook of Online Research Methods (pp. 141-160). Los Angeles, London, New Delhi, Singapore: Thousand Oaks: Sage Publications.

Kaplan, A. \& M. Haenlein, M. (2010) "User of the world, unite! The challenges and opportunities of social". Business Horizons, 53 (1), pp. 59-68.

Logan, K., Bright, L. \& Gangadharbatla, H. (2012), "Facebook versus television: Advertising value perceptions among females". Journal of Research in Interactive Marketing, 6(3), pp. 164-179.

Montes, E. (2010), "La revolución de Internet". Revista de la Facultad de Ciencias Contables, 17 (34), 209-214.

Moya, E. (2014). "Inteligencia en redes sociales: despertando el potencial del community manager". Barcelona, España: Editorial UOC.

Nunnally, J. (1978), Psychometric Theory, McGraw-Hill, New York, NY, 1978.

$$
\text { REDMARKA IMARKA-Universidad de A Coruña - CIECID }
$$


Pew Research (2013). "Social Media Update 2013". Disponible en http://www.pewinternet.org. Último acceso 3 mayo 2017.

Phillips, B. Miller, J. \& McQuarrie, E. (2014), "Dreaming out loud on Pinterest". International Journal of Advertising, 33(4), pp. 633-655.

Sicilia, M., Palazón, M. \& López, M. (2016), "Brand pages as a communication tool: A state of the art and a research agenda". En P. Pelsmacker (Ed.), Advertising in New Formats and Media: Current Research and Implications for Marketers (pp. 169-190). United Kingdom, North America, Japan, India, Malaysia, China: Emerald Group Publishing Limited.

We Are Social (2016), "Estudio sobre el estado de internet y las redes sociales en 2016". Disponible en <http://franbarquilla.com/> Último acceso: 23 de mayo de 2017.

Yu, J. (2014), "We look for social, not promotion: Brand post strategy, consumer emotions, and engagement-a case study of the Facebook brand pages". Journal on Media \& Communications, 1(2), pp. 28-37.

Zhang, Y. \& Buda, R. (1999), "Moderating effects of need for cognition on responses to positively versus negatively framed advertising messages". Journal of Advertising, 28(2), pp. 1-15. 